\title{
Novel insights into the charge storage mechanism in pseudocapacitive vanadium nitride thick films for high-performance on-chip micro-supercapacitors
}

Kevin Robert ${ }^{1,2}$, Didier Stiévenard ${ }^{1}$, Dominique Deresmes ${ }^{1}$, Camille Douard ${ }^{2,3}$, Antonella Iadecola $^{2}$, David Troadec ${ }^{1}$, Pardis Simon ${ }^{4}$, Nicolas Nuns ${ }^{4}$, Maya Marinova ${ }^{4}$, Marielle Huvé ${ }^{4}$, Pascal Roussel $^{4}$, Thierry Brousse ${ }^{2,3^{*}}$ and Christophe Lethien ${ }^{1,2^{*}}$

${ }^{1}$ Institut d'Electronique, de Microélectronique et de Nanotechnologies (IEMN), Université de Lille, CNRS, Centrale Lille, ISEN, Université de Valenciennes, UMR 8520 - IEMN, F-59000 Lille, France

${ }^{2}$ Réseau sur le Stockage Electrochimique de l'Energie (RS2E), CNRS FR 3459, 33 rue Saint Leu, 80039 Amiens Cedex, France

${ }^{3}$ Institut des Matériaux Jean Rouxel (IMN), CNRS UMR 6502 - Université de Nantes, 2 rue de la Houssinière BP32229, 44322 Nantes cedex 3, France

${ }^{4}$ Unité de Catalyse et de Chimie du Solide (UCCS), Fédération Chevreul, Université de Lille, CNRS, Centrale Lille, ENSCL, Université d'Artois, UMR 8181 - UCCS, F-59000 Lille, France

*Correspondence to: $\underline{\text { christophe.lethien@ univ-lille.fr } \& \text { thierry.brousse@ univ-nantes.fr }}$ 


\section{Abstract}

The Internet of Things, enabled by a worldwide network of interconnected sensors, is limited in its large-scale deployment of nomadic miniaturized devices due to the bounds of energy selfsufficiency. One possible solution, albeit challenging, is constructing on-chip pseudocapacitive micro-supercapacitors. Herein, we achieve the collective fabrication of micro-supercapacitors based on sputtered bi-functional vanadium nitride films. Our reported surface and volumetric capacitance values $\left(1.2 \mathrm{~F} \mathrm{~cm}^{-2}\right.$ and $>700 \mathrm{~F} \mathrm{~cm}^{-3}$, respectively) compete well with those of cuttingedge transition metal oxide/nitride materials, and exceed those of standard carbon electrodes. The pseudocapacitive behavior of vanadium nitride in aqueous electrolyte remaining unclear, research involving in situ/operando characterization techniques on sputtered vanadium nitride film in aqueous electrolyte was conducted — thus enabling us to unveil its charge storage process here.
\end{abstract}




\section{Introduction}

Secondary batteries ${ }^{1}$ are conventional electrochemical energy storage systems used to power nomadic devices. Unfortunately, the mobility of such devices is limited by lengthy charging times and a deterioration in battery performance at upwards of a few thousand cycles. The Internet of Things (IoT) is a revolutionary technology aimed at creating an ecosystem of interconnected devices in order to improve our daily lives ${ }^{2}$. Autonomy and mobility are crucial parameters with respect to powering IoT micro-devices, and energy storage systems capable of delivering high energy density at high charge / discharge rates are a fundamental prerequisite for next-generation IoT networks ${ }^{3}$. Lithium micro-batteries (MBs) ${ }^{4,5}$ and carbon micro-supercapacitors (MSCs) ${ }^{6-8}$ are currently the most viable candidates for powering smart and miniaturized sensors. Regarding the former, such MBs are hampered by the low charge / discharge rates whereas the latter are limited to the low capacitance of the carbon electrodes. MSCs based on pseudocapacitive materials are a class of electrochemical capacitors where fast redox reaction occur near the surface of the electrode material ${ }^{9-12}$, providing higher energy densities than carbon-based MSCs. However, the main issue with these is designing a pseudocapacitive material that combines rapid ion diffusion and fast electron transport in thick electrodes. Following the discovery of the pseudocapacitive properties of $\mathrm{RuO}_{2}{ }^{13}$, numerous transition metal oxides - $\mathrm{TMO}-\left(\mathrm{MnO}_{2}, \mathrm{~T}-\mathrm{Nb}_{2} \mathrm{O}_{5} \ldots .\right)^{14-19}$ and a two-dimensional transition metal carbide - namely MXene ${ }^{20-22}$ - were investigated. Whereas TMOs show low electrical conductivity, MXene combine rapid electron transport in the 2D metal carbide with fast redox reactions at the TMO-like surface. However, depositing MXene films using deposition methods issuing from the microelectronics industry proves challenging when a scaleup of the technology is required. 
Transition Metal Nitrides (TMN) are a widely-studied class of materials owing to their favorable electrical and electrochemical properties. Molybdenum and vanadium nitrides ${ }^{23,24}$ clearly demonstrated outstanding pseudocapacitive properties $\left(>700 \mathrm{~F} \mathrm{~g}^{-1}\right)$ in aqueous electrolyte, even though the charge storage mechanism of vanadium nitride remained unclear ${ }^{24,25}$. Sputtered bifunctional vanadium nitride (VN) film was shown to be an intrinsically efficient current collector and electrode material for on-chip MSCs due to its electrochemical and electrical properties ${ }^{12}$. This sputtering based-strategy clearly facilitates the scaling up of the technology, by following the same roadmap that we recently proposed for on-chip MSCs based on nanoporous carbon-derived carbide films ${ }^{6}$. Herein, various scientific issues ranging from fundamental concerns to the technological fabrication of MSCs on a silicon wafer are addressed. The charge storage process occurring in sputtered $\mathrm{VN}$ films is thoroughly investigated in order to explain their remarkably high areal and volumetric capacitances. To this end, we employed a combination of numerous advanced characterization techniques such as Operando X-Ray Absorption Spectroscopy under synchrotron radiation, as well as powerful surface techniques like X-ray Photoelectron Spectroscopy (XPS) coupled with Time-of-Flight Secondary Ion Mass Spectrometry (ToF-SIMS) and Electron Energy Loss Spectroscopy (EELS) analysis at the nanoscale in a Transmission Electron Microscope (TEM). Our findings show that we have succeeded in extending the limits of VN films deposited via production-compatible microelectronic deposition methods in order to attain the highest areal $\left(1.2 \mathrm{~F} \mathrm{~cm}^{-2}\right)$ and volumetric $\left(>700 \mathrm{~F} \mathrm{~cm}^{-3}\right)$ capacitance values hitherto reported, to our knowledge, in the domain of MSCs in aqueous electrolyte. Additionally, in situ Atomic Force Microscopy (AFM) imaging of VN-based MSCs revealed their favorable cycling behavior ( 50000 cycles). It can thus be concluded that the performance of these MSCs certainly 
fulfills the requirements of IoT miniaturized devices in terms of rate capabilities and long-term cycling.

\section{Charge Storage mechanism in vanadium nitride films}

Figure 1A depicts the used strategy to investigate the charge storage process in sputtered VN films. To maximize the film capacitance, it is important to clearly identify and understand the key role of the sputtering temperature on the VN morphology. SEM cross-section analysis and AFM top-surface imaging of the $340 \mathrm{~nm}$-thick sputtered VN films are reported in Figure 1B and Figure S1 vs the heating temperature. The higher the temperature, the higher the ad-atoms' mobility ${ }^{12,26}$, the lower the inter-columnar spacing. At $20{ }^{\circ} \mathrm{C}$, the RMS roughness was $3.9 \mathrm{~nm}$ indicating the homogeneity of the film's surface (Figure 1C). For higher temperatures, the roughness increased up to $16 \mathrm{~nm}$, in good agreement with the observation of increasingly dense bright spots. These spots correspond to pyramidal patterns (Figure 1B).

Judging by these AFM images, and based on recent methods published by our group ${ }^{27}$, it was deduced that the projected length, $\mathrm{L}_{\mathrm{p}}$ (Figure 1C), decreased from 36 to $16.5 \mu \mathrm{m}$. Concurrently, the contribution of the pyramids to $L_{p}$ increased from 0 up to $14 \mu \mathrm{m}$ for high temperature deposition. The AFM images in Figure 1D highlight the formation of a pyramidal-type pattern at $350{ }^{\circ} \mathrm{C}$ for $2 \mu \mathrm{m}$-thick films, confirming the formation of pyramids at high temperatures.

Finally, based on $\mathrm{L}_{\mathrm{p}}$, we evaluated the specific surface, $\mathrm{S}_{\mathrm{e}}$, of 340-nm thick VN films (Figure 1E), which decreased from 12.5 down to $5 \mathrm{~cm}^{2}$ per $\mathrm{cm}^{2}$ footprint as the temperature shifted from room temperature (RT) to $450{ }^{\circ} \mathrm{C}$. Electrochemical analysis of those VN films was then conducted. As expected, the cyclic voltammogram (CV) exhibited a rectangular shape (Figure 1F), and the higher the temperature, the lower the $\mathrm{CV}$ areas. On one hand, at $5 \mathrm{mV} \mathrm{s}^{-1}$, the capacitance 
decreased from 42 to $30 \mathrm{mF} \mathrm{cm}{ }^{-2}$ when the temperature was increased from $\mathrm{RT}$ to $450{ }^{\circ} \mathrm{C}$ (Figure 1G). On the other hand, the electrical conductivity (Figure 1G) increases linearly with the temperature. To maximize the specific surface, the areal capacitance while keeping sufficiently high the conductivity, the compromise consists in depositing the vanadium nitride film at $100{ }^{\circ} \mathrm{C}$. This study confirmed the key role that temperature plays in determining pyramidal patterns, capacitance values and specific surface areas.

In order to investigate the charge storage mechanism in sputtered and crystallized VN films (Figure S1, Supplementary Materials (SM) section), surface analyses were initially carried out on $100 \mathrm{~nm}$-thick sample. Three square-shaped craters were drilled into the VN film using the ToFSIMS equipment. The $1^{\text {st }}$ crater was bored down to the silicon substrate to assess the etching rate of the $\mathrm{VN}$ and $\mathrm{Si}_{3} \mathrm{~N}_{4}$ layers. The $2^{\text {nd }}$ crater was stopped approximately in the middle of the $\mathrm{VN}$ layer $(\approx 50 \mathrm{~nm})$, while the $3^{\text {rd }}$ crater was etched down to the $\mathrm{VN} / \mathrm{Si}_{3} \mathrm{~N}_{4}$ interface (Figure $2 \mathrm{~A} \&$ Figure S2A). The ToF-SIMS depth profile reveals the presence of vanadium nitride, oxide and oxynitride species (Figure 2B). Then, the sample was transferred from the ToF-SIMS to the XPS chamber under vacuum in order to analyze the film at the surface and inside the $2^{\text {nd }}$ and $3^{\text {rd }}$ SIMS craters.

Figure 2C shows the high-resolution XPS spectra for V $2 p$ and O $1 s$ core levels from the surface to the $\mathrm{VN} / \mathrm{Si}_{3} \mathrm{~N}_{4}$ interface: we found an oxygen component at the surface as well as in the craters. The V $2 p$ core level at the VN surface is rather complex. The first contribution of the V $2 p_{3 / 2}$ level is measured at $513.70 \mathrm{eV}$. This is consistent with the formation of the $\mathrm{VN}$ species. In order to fit the spectrum adequately, two additional V $2 p$ doublets with V $2 p_{3 / 2} \mathrm{BE}$ at 514.8 and $516.8 \mathrm{eV}$ were required. Those peaks were observed in the $\mathrm{V} 2 p$ core level spectra of the $2^{\text {nd }}$ and $3^{\text {rd }}$ craters, but with a lower intensity as compared to the surface. As concerns the XPS, considering the presence 
of oxygen and the oxynitride peak in $\mathrm{N} 1 s$ spectra (Figure S2D), the $2^{\text {nd }}$ contribution can be ascribed to a vanadium (III) oxide or $\mathrm{VN}_{1-\mathrm{x}} \mathrm{O}_{\mathrm{x}}$ oxynitride, whereas the last peak at higher $\mathrm{BE}$ can be ascribed to a vanadium (IV) oxide ${ }^{28}$. To summarize, ToF-SIMS paired with XPS analyses confirm the presence of vanadium nitride, vanadium oxide (+III and + IV) and a small amount of vanadium oxynitride in the films, from their surface to the $\mathrm{VN} / \mathrm{Si}_{3} \mathrm{~N}_{4}$ interface.

So as to obtain further insight into the charge storage process and to refine the XPS conclusions, additional investigations were deemed necessary. The charge storage mechanism in $\mathrm{VN}$ nanocrystals was studied ${ }^{24}$ by Kumta et al in 2006, whereby ex situ XPS analysis confirmed the formation of a vanadium oxide shell $(0.5 \mathrm{~nm})$ surrounding the vanadium nitride core of the nanocrystals. However, they found it difficult to predict the type of vanadium oxides $\left(\mathrm{V}_{\mathrm{x}} \mathrm{O}_{\mathrm{y}}\right)$ via ex situ XPS analyses. To address this issue, we opted to study $1 \mu \mathrm{m}$-thick sputtered VN films by operando XAS at the V-K edge in a $\mathrm{KOH}$ electrolyte. Additionally, EELS/TEM analysis was carried out to identify the position of the vanadium oxide layer within the sputtered columnar vanadium nitride film. The experimental method for the operando XAS measurement (Figure S3) is detailed in the SM, where all the parameters were optimized to maximize the signal to noise ratio (Figure S4A-F).

The CV ( $2^{\text {nd }}$ cycle) is shown in Figure 3A. Fast data acquisition of the XAS signal allows for a fine sampling of the charge storage process, so as to achieve accurate monitoring of the oxidation state of the transition metal. Absorption spectra reported in Figure 3B clearly highlight a shift of the absorption threshold upon charge / discharge cycling. The plot showing the energy shift of the applied potential exhibits a triangular shape (Figure 3C), similar to that of pseudocapacitive material ${ }^{29,30}$. To find the vanadium species involved in the charge storage mechanism, in Figure 3D we plot the evolution of the absorption edge for $\mathrm{V}_{\mathrm{x}} \mathrm{O}_{\mathrm{y}}$ (cross points) and $\mathrm{VN}$ (square point) 
reference compounds (Figure S4G) vs the valence of the vanadium element. In this graph, we also show the energy absorption edges (circular points) measured during the operando XAS analysis (Figure 3B-C and S4H-I). Not surprisingly, this graph clearly indicates that VN could not be responsible for the pseudocapacitive process - a vanadium oxide layer seems to be the key player in the fast charge transfer occurring during the redox process, confirming the hypothesis proposed by Kumta et al. While in 2006 we found it difficult to find the type of $\mathrm{V}_{\mathrm{x}} \mathrm{O}_{\mathrm{y}}$ involved in the process by ex situ XPS ${ }^{24}$ - as observed in our XPS / ToF-SIMS experiments - the originality of this, hitherto unreported, study deals with the accurate determination of the vanadium oxidation degree in the vanadium oxide species upon charge / discharge cycling. From these operando XAS measurements, the average oxidation state was found to vary from 3.56 to 3.66 (correlated with XPS analyses), meaning that the XANES capacitance is approximately $88 \mathrm{mF} \mathrm{cm}^{-2}$. This capacitance is a perfect match with that of $1 \mu \mathrm{m}$-thick VN film $\left.(\sim 90 \mathrm{mF} \mathrm{cm})^{-2}\right)$. Once we had demonstrated that a mixed vanadium oxide $\mathrm{V}_{2} \mathrm{O}_{3} / \mathrm{VO}_{2}$ - type is involved in the charge storage mechanism, the question arose as to where the $\mathrm{V}_{\mathrm{x}} \mathrm{O}_{\mathrm{y}}$ are located within the $\mathrm{VN}$ film. To tackle this issue, TEM analysis and EELS spectroscopy with a nanosized-spot was performed on $7 \mu \mathrm{m}$-thick sputtered VN film. The Figure 3E-F perfectly illustrates the columnar morphology of the film. Between two VN columns, we observe brighter contrast in the TEM image and darker areas in the HAADF images, corresponding to porosities and/or areas with lower atomic density. Figure 3G shows the EELS spectra measured within the VN column (blue line) and between two VN columns (pink line). The EELS spectrum (blue line) in the VN column shows the $\mathrm{V}-\mathrm{L}_{3,2}$ edge at $517 \mathrm{eV}$, and the negligible intensity at $531 \mathrm{eV}$ corresponding to the $\mathrm{O}-\mathrm{K}$ edge. The pink line clearly indicates a shift of V-L $\mathrm{L}_{3,2}$ edge towards higher energy $(518.1 \mathrm{eV})$, accompanied by a considerable 
increase of the $\mathrm{O}-\mathrm{K}$ edge at $531 \mathrm{eV}$. We observe a higher oxidation state of $\mathrm{V}$ in the area between the $\mathrm{VN}$ columns, corresponding to the formation of $\mathrm{V}_{\mathrm{x}} \mathrm{O}_{\mathrm{y}}$.

Based on these findings — finally able to fully comprehend the charge storage process involved in sputtered VN films operating in aqueous electrolyte — we reached the conclusion that the sputtered VN film acts as a conductive scaffold for electron transport, while the amorphous mixedvalence vanadium oxides (+III / + IV), located at the edge of each column, are the redox-active material allowing fast charge transfer (Figure 1A). This conclusion resonates with that of a previous publication investigating MXene electrodes, where the conductive carbide layer enables rapid electron transport and where the TMO-like surface is the redox-active center ${ }^{22}$. Such findings reaffirm the suitability of sputtered VN for MSC applications.

\section{Electrode design providing high areal and volumetric performance}

As previously demonstrated, capacitance of the $\mathrm{VN}$ films decreases and electrical conductivity increases at higher deposition temperatures. Consequently, an intermediate temperature of $100{ }^{\circ} \mathrm{C}$ was chosen for the sputtering deposition since, at this temperature, $\mathrm{VN}$ is a suitable current collector and an efficient pseudocapacitive electrode. To enhance the surface capacitance, an interesting approach is to deposit a thicker layer providing that (1) the deposition method is compatible with the microelectronics industry, and (2) that the electrical conductivity of the electrode material is sufficiently high for fast electron transport. AFM analysis is shown in Figure

4A where the evolution of $L_{p}$ and $S_{e}$ vs the film thickness is reported. The top-view and the SEM cross-section images, the roughness, the evolution of the electrical conductivity as well as the XRay Diffraction analyses of the VN films are shown in Figure S5, confirming the polycrystalline nature of the VN films (PDF card 000-035-1768) and the good conducting properties of those VN 
films. The $S_{e}$ is clearly enhanced to a $70 \mathrm{~cm}^{2}$ per $\mathrm{cm}^{2}$ footprint area for $16 \mu \mathrm{m}$-thick VN film. As a result, the areal capacitance is increased as depicted in the CV plots (Figure 4B). Further discussion regarding the ion kinetics within the VN films is provided in the SM. As mentioned, the areal and volumetric capacitance values are remarkable and unique: a surface capacitance of up to $1.2 \mathrm{~F} \mathrm{~cm}^{-2}$ was measured at $5 \mathrm{mV} \mathrm{s}^{-1}$ for $16 \mu \mathrm{m}$-thick VN film (Figure 4C), which is 6 times higher than our previous results ${ }^{12}$. This translates into a volumetric capacitance of $700 \mathrm{~F} \mathrm{~cm}^{-3}$. For thinner films, the volumetric capacitance value increases up to $1300 \mathrm{~F} \mathrm{~cm}^{-3}$ (Figure 4C). It is noteworthy that the $16 \mu$ m-thick $\mathrm{VN}$ film retains more than $80 \%$ of the initial capacitance for 50000 cycles (Figure 4D). A benchmarking of the achieved areal performance (square points) as compared to state-of-the-art (pseudo)capacitive electrodes is furnished in Figure 4E. The $7 \mu \mathrm{m}$ thick carbon-derived carbide (CDC) film ${ }^{31,32}$ delivers $0.1 \mathrm{~F} \mathrm{~cm}^{-2}$ in organic electrolyte ${ }^{6,33}$. In aqueous electrolyte ${ }^{6}, 5 \mu$ m-thick CDC films deliver up to $0.2 \mathrm{~F} \mathrm{~cm}^{-2}$. MXene $\mathrm{Ti}_{3} \mathrm{C}_{2}$-T electrode is a very attractive material, also from the point of view of areal and volumetric capacitances: $5 \mu \mathrm{m}-$ thick $\mathrm{Ti}_{3} \mathrm{C}_{2}$ - $\mathrm{T}$ "clay" electrodes deliver up to a $0.4 \mathrm{~F} \mathrm{~cm}^{-2} / 900 \mathrm{~F} \mathrm{~cm}^{-3}$ capacitance values when measured in $1 \mathrm{M} \mathrm{H}_{2} \mathrm{SO}_{4}{ }^{34}$. The volumetric capacitance of a $\mathrm{Ti}_{3} \mathrm{C}_{2}$ - $\mathrm{T}$ electrode $(3 \mu \mathrm{m}$-thick) decreases to $400 \mathrm{~F} \mathrm{~cm}^{-3}$ in $1 \mathrm{M} \mathrm{KOH}^{20}$. The corresponding areal capacitance value $\left(120 \mathrm{mF} \mathrm{cm}^{-2}\right)$ is twice as low as the one we obtained (Figure S6C) with a $2.5 \mu \mathrm{m}$-thick VN film $\left(>250 \mathrm{mF} \mathrm{cm}^{-}\right.$ 2/ $1000 \mathrm{~F} \mathrm{~cm}^{-3}$ ) in $1 \mathrm{M} \mathrm{KOH}$. Moreover, one faces a similar issue here with respect to producing MXene ${ }^{20,21,34}$ films via deposition methods that are compatible with the microelectronics industry and suitable for MSC applications. These sputtered VN films thus provide the most favorable compromise between surface and volumetric capacitances when compared to cutting-edge electrodes, while keeping the electrical conductivity high in the absence of a conductive agent in order to facilitate fast electron transport for miniaturized devices. Having reached a fundamental 
understanding of the charge storage process and film optimizations, we succeeded in fabricating on-chip interdigitated MSC based on VN electrodes on a 3-inch silicon wafer. An assessment of the electrode degradation upon cycling was carried out using in situ AFM in $1 \mathrm{M} \mathrm{KOH.}$

\section{Micro-supercapacitors based on VN films}

CDC films ${ }^{6}$ have already been analyzed by AFM in ionic liquid electrolyte ${ }^{35}$ to track the volume expansion of the electrode upon cycling. To ascertain the aging of the VN electrode, we develop an experimental test setup (Figure S7) in order to trace the volume expansion of the interdigitated electrodes tested in 1M KOH (Figure 5A). A movie demonstrating the in situ characterization of the MSC in $1 \mathrm{M} \mathrm{KOH}$ is furnished in the SM. The interdigitated topology is illustrated in Figure 5B, where the etching process was stopped at the $\mathrm{VN} / \mathrm{Si}_{3} \mathrm{~N}_{4}$ interface. AFM imaging of the VN electrode - firstly in the absence of liquid, then soaked in water and then in $1 \mathrm{M} \mathrm{KOH}$ electrolyte, respectively — was performed prior to in situ analysis (Figure S7C and S7D). The AFM images attest to the absence of volume expansion and chemical degradation in either the electrode or the AFM tip (90 minutes test). We then studied the degradation of the VN film upon cycling in $1 \mathrm{M}$ $\mathrm{KOH}$ by applying a voltage plateau from $-0.4 \mathrm{~V}$ down to $-1 \mathrm{~V}$ vs $\mathrm{Hg} / \mathrm{HgO}$ (and inversely) for 2 minutes on the $1^{\text {st }}$ electrode (Figure 5B). The $2^{\text {nd }}$ electrode remained unbiased so as to compare the potential volume expansion. From cross-section AFM images, we measured the thickness of the VN operating electrode, using the $\mathrm{Si}_{3} \mathrm{~N}_{4}$ surface as a reference (Figure $5 \mathrm{C}$ ). The thickness of the $\mathrm{VN}$ electrode is shown to remain constant regardless of the applied potential, i.e. there is no expansion of the VN electrode upon cycling, validating the long-term cycling (50 000 cycles). Finally, the performance of on-chip MSCs are evaluated. Galvanostatic charge / discharge cycling is shown in Figure 5D. The energy densities of $7 \mu \mathrm{m}$-thick and $16 \mu \mathrm{m}$-thick MSCs (Ragone plot 
- Figure 5E) reach 10 and $25 \mu \mathrm{Wh} \mathrm{cm}^{-2}$, respectively. The $16-\mu \mathrm{m}$ thick MSC exhibits an energy density which is 16 times higher that of MSCs based on CDC films ${ }^{6}$ tested in $1 \mathrm{M} \mathrm{H}_{2} \mathrm{SO}_{4}$. The maximum power density remains stable at around $4 \mathrm{~mW} \mathrm{~cm}{ }^{-2}$, regardless of film thickness.

Our work provides a fresh perspective on the charge storage mechanism of sputtered VN films in $\mathrm{KOH}$ electrolyte. We succeed in fine-tuning the VN properties in order to synthesize bi-functional films (i.e. for use as both current collector \& electrode material for on-chip MSCs). These bifunctional VN thick films $(16 \mu \mathrm{m})$ exhibit both high specific area $\left(70 \mathrm{~cm}^{2}\right.$ per $\left.\mathrm{cm}^{2}\right)$ and areal capacitance $\left(1.2 \mathrm{~F} \mathrm{~cm}^{-2}\right)$, as well as both high volumetric capacitance $\left(>700 \mathrm{~F} \mathrm{~cm}^{-3}\right)$ and capacitance retention (50 000 cycles). It is noteworthy that these MSCs are constructed using a CMOS-compatible microfabrication technique and tested using in situ AFM methods to verify cycling stability. In light of the above, the present study clearly paves the way for the collective fabrication of miniaturized energy storage devices on a silicon wafer, and thus for the efficient powering of next-generation IoT micro-devices. 
A

Charge Storage Mechanism Investigation of sputtered vanadium nitride electrodes for on chip micro-supercapacitor (MSC)

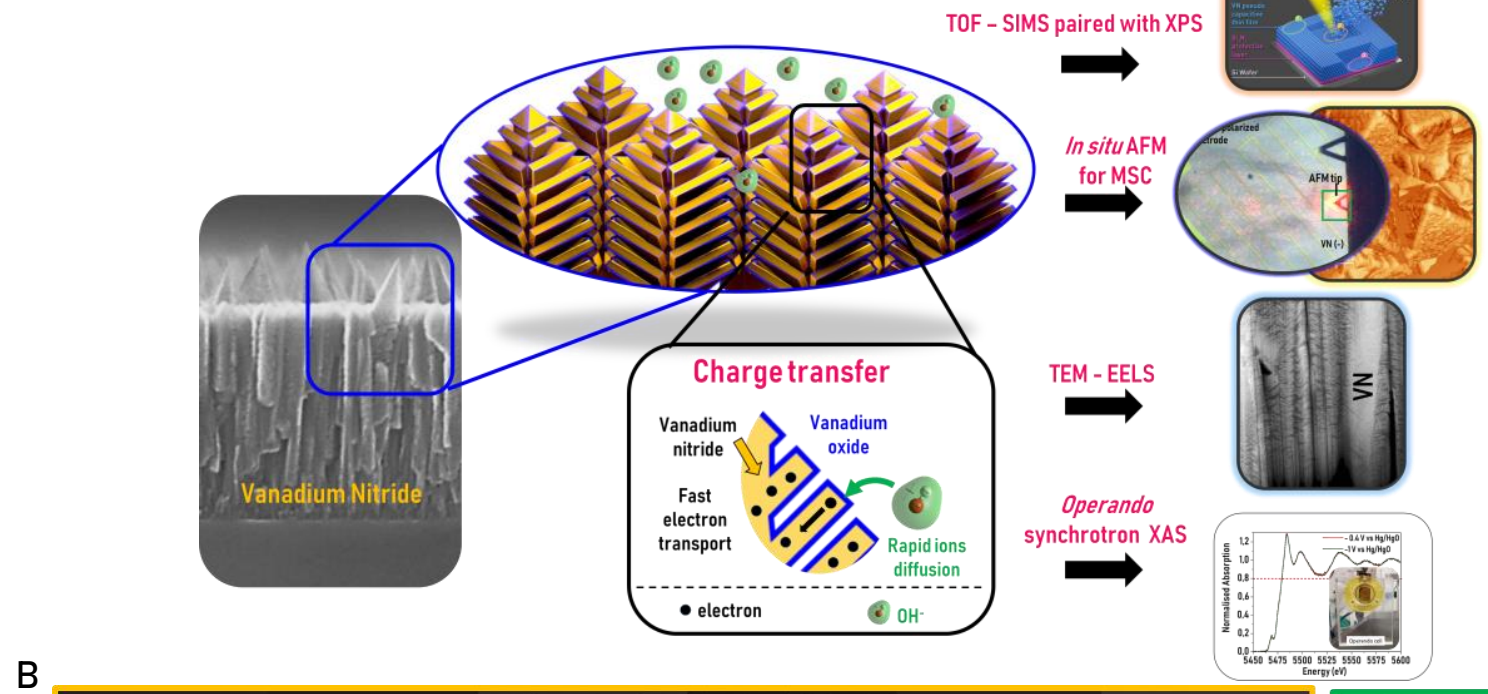

B
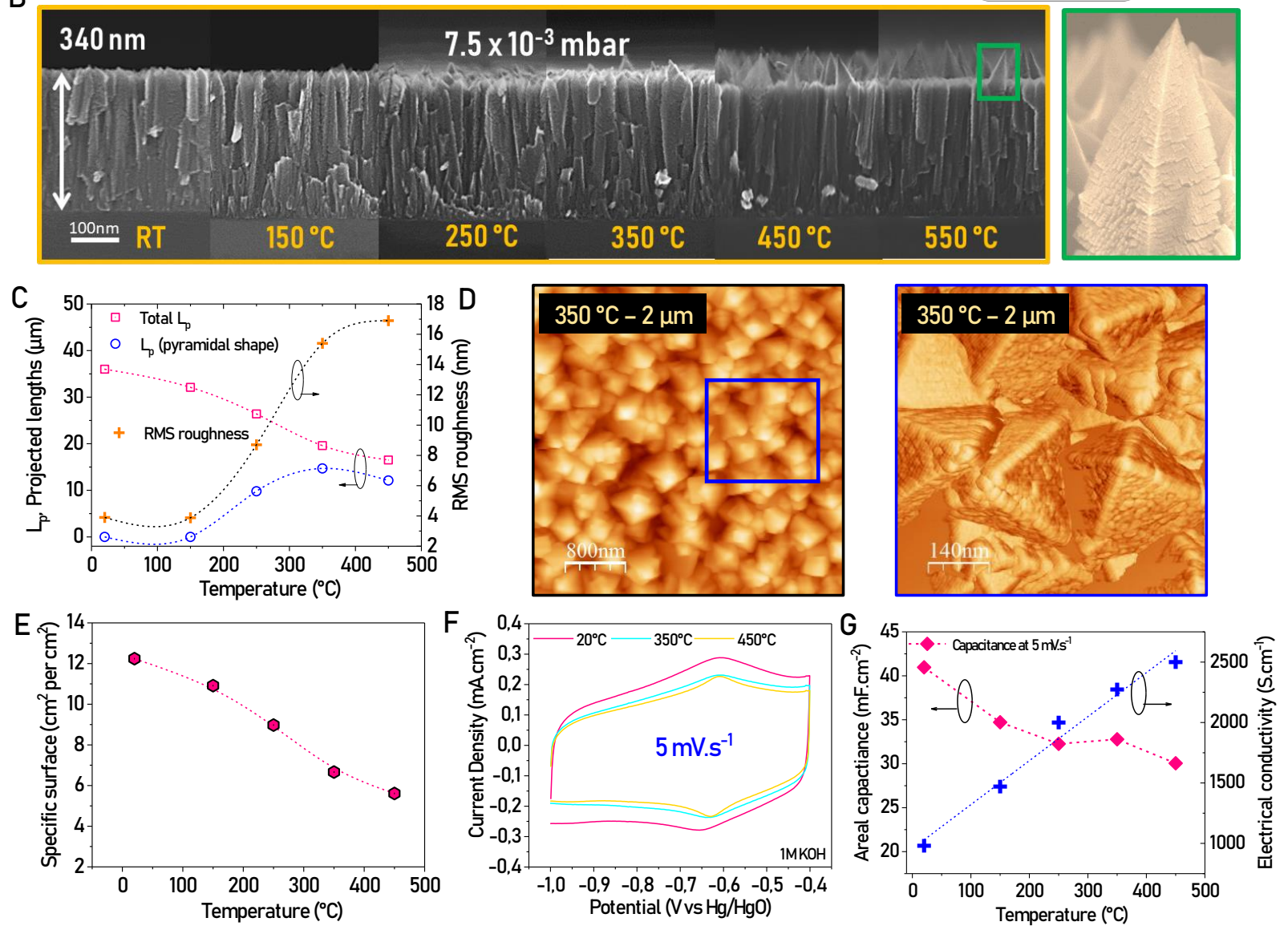

Figure 1 - A. Overview of the strategy used to study the charge storage process. B. SEM crosssection imaging of the VN films. C. Plots of $\mathrm{L}_{p}$ and roughness vs the temperature. D. AFM top 
surface and amplitude error imaging of the $2 \mu \mathrm{m}$-thick VN films deposited at $350^{\circ} \mathrm{C}$. E. Evolution of $\mathrm{S}_{\mathrm{e}} \mathrm{vs}$ the temperature. F. CV profile of the $340 \mathrm{~nm}$-thick VN films vs the deposition temperature at $5 \mathrm{mV} \cdot \mathrm{s}^{-1}$ in $1 \mathrm{M} \mathrm{KOH}$. G. Evolution of the areal capacitance at $5 \mathrm{mV} \cdot \mathrm{s}^{-1}$ and the electrical conductivity vs temperature. 

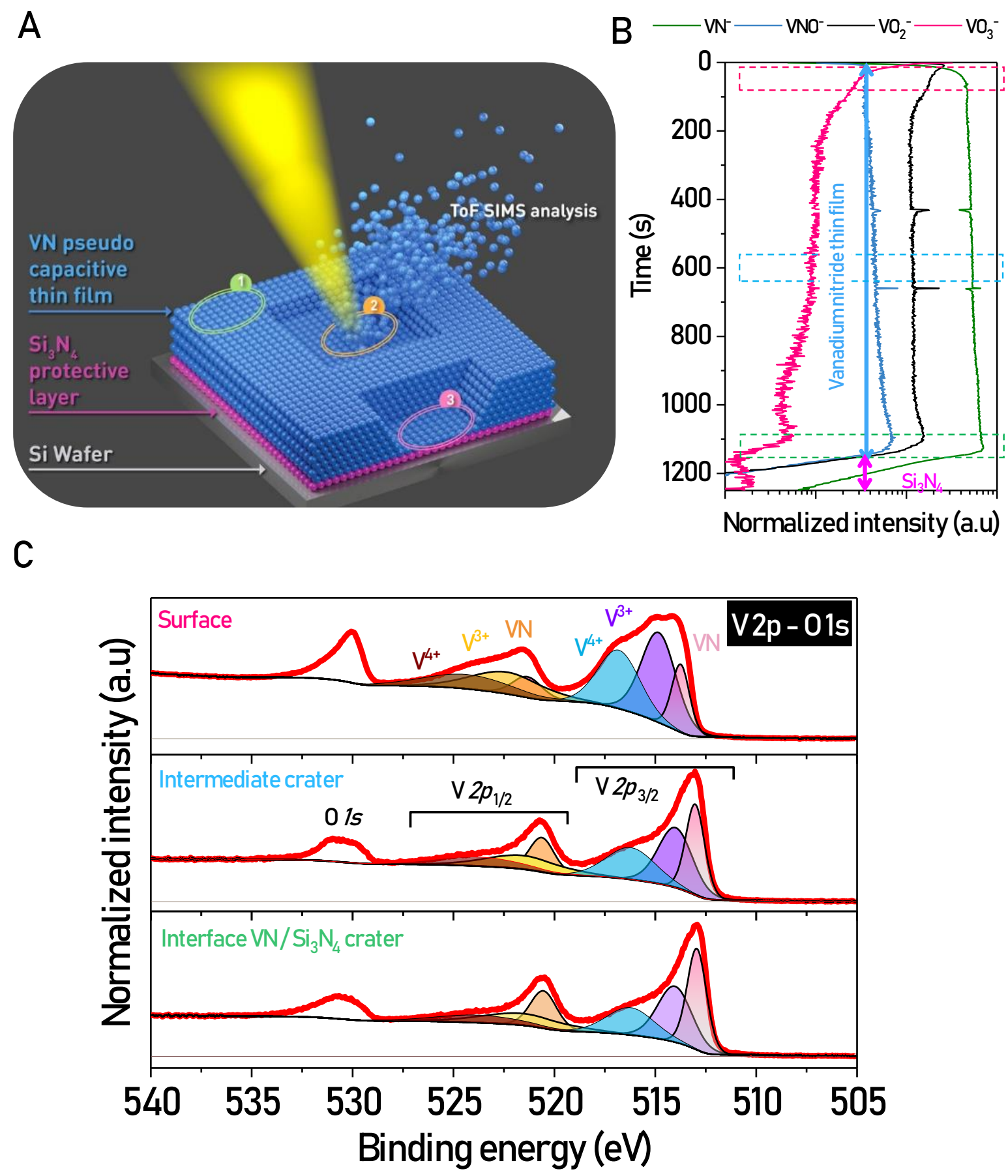

Figure 2 - A. Overview of the combined ToF-SIMS / XPS analyses at the surface, in the middle of the VN film, and at the $\mathrm{VN} / \mathrm{Si}_{3} \mathrm{~N}_{4}$ interface. B. ToF-SIMS depth profile of the VN film from 
the surface to the $\mathrm{VN} / \mathrm{Si}_{3} \mathrm{~N}_{4}$ interface. C. High resolution XPS spectra (V $2 p-\mathrm{O} 1 s$ core-level region) of the VN film. 

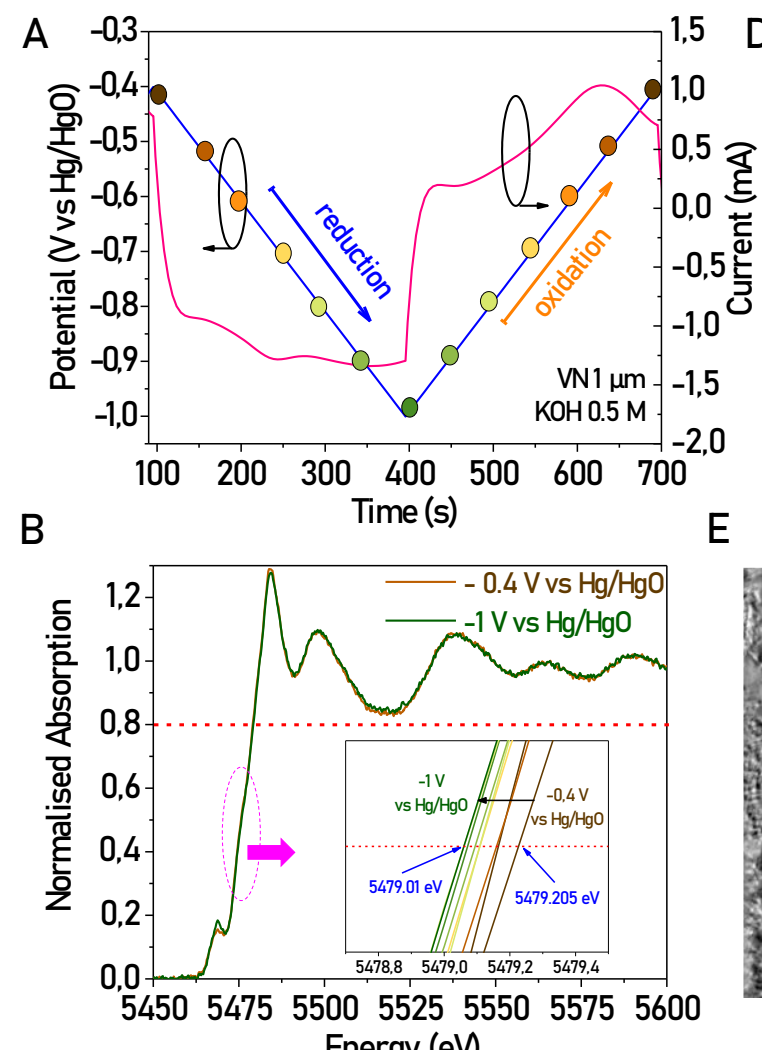

C

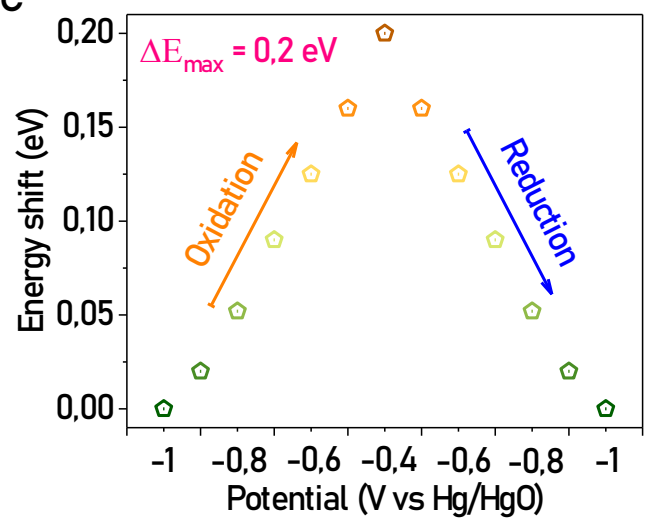

G
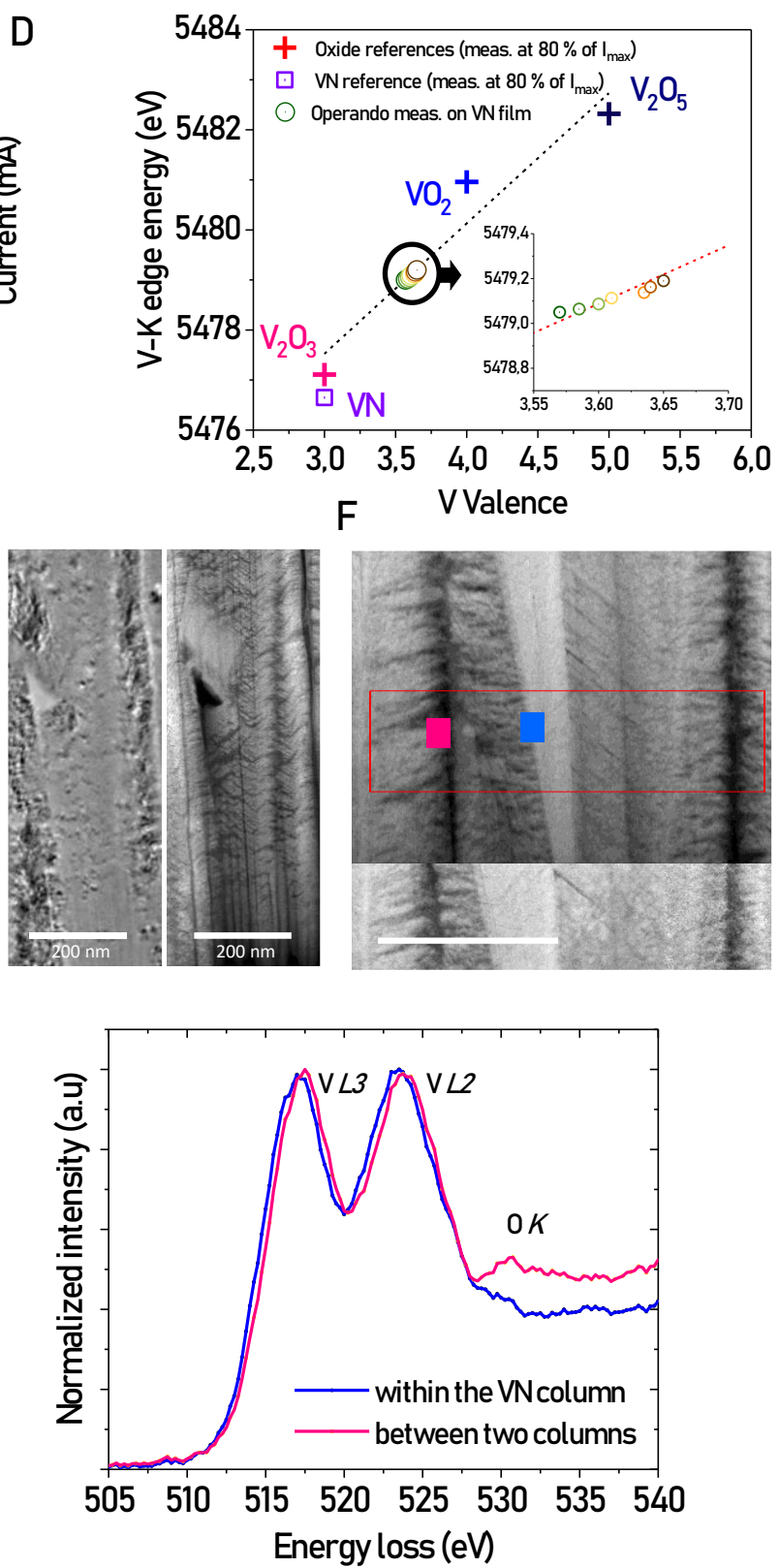

Figure 3 - Investigation of the Charge Storage Mechanism in the sputtered VN Films. A. Plots of the current (pink line) and the potential (blue line) vs the time. B. V K-edge XANES spectra of the VN electrode; the inset represents a focus of the edge position at $80 \%$ of edge step when the potential varies between -0.4 and $-1.0 \mathrm{~V}$ vs $\mathrm{Hg} / \mathrm{HgO}$ (reduction process). C. Energy shift as a function of the working potential, highlighting the oxidation and reduction processes. D. Plots of the energy position during the oxidation process as a function of the vanadium valence. E. TEM 
and HAADF images of VN films. F. HAADF image of the VN film illustrating the two areas where EELS analysis is performed (blue square within the VN column, and pink square between two columns). G. Corresponding EELS spectra including both V-L $\mathrm{L}_{3,2}$ edge and O-K edge. 


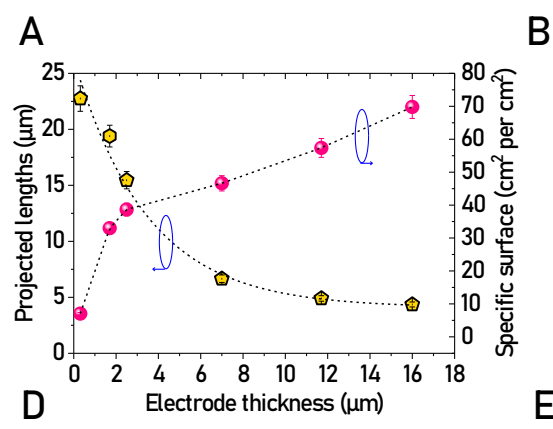

$B$
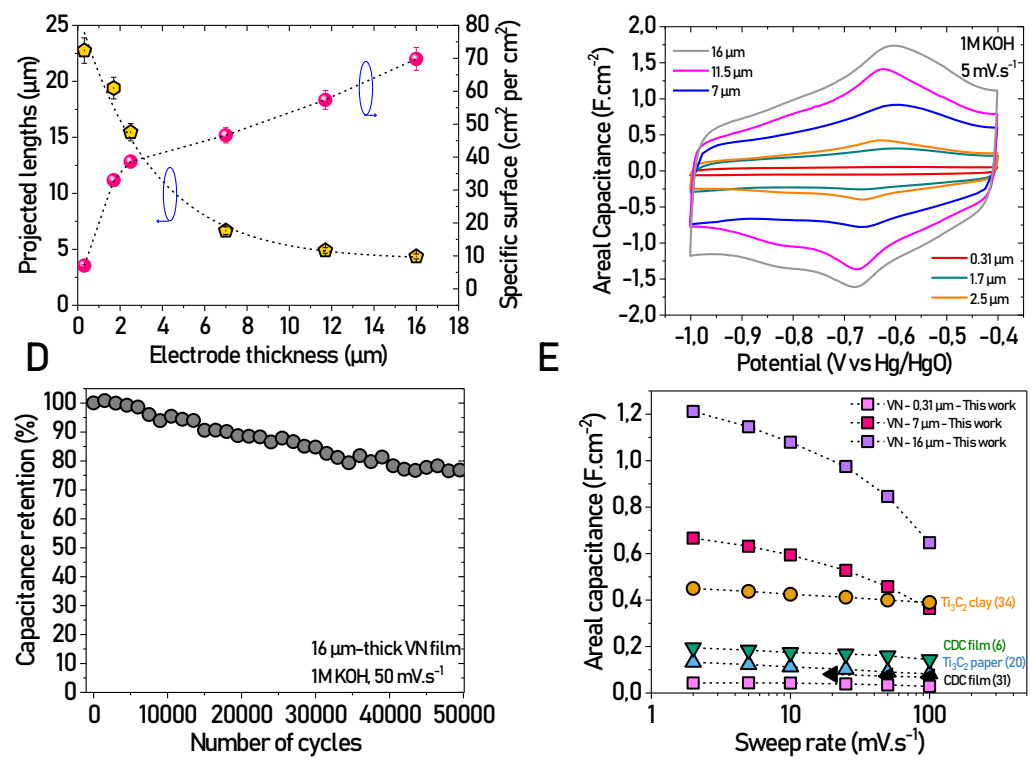

E

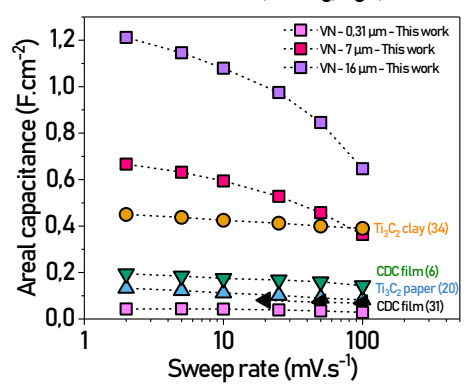

C
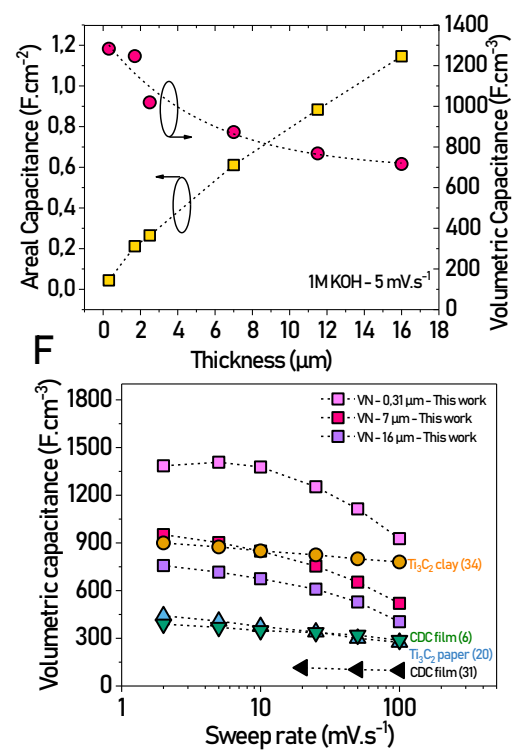

Figure 4 - Performance of the sputtered VN films. A. Evolution of the $L_{p}$ and $S_{e}$ vs the film thickness. B. CV plot of the VN electrode vs the thickness. C. Evolution of the areal and volumetric capacitances vs the thickness. D. Capacitance retention vs the number of cycles (16 $\mu \mathrm{m}$-thick film) at $50 \mathrm{mV} \mathrm{s}^{-1} . \mathbf{E} / \mathbf{F}$. Benchmarking the VN performance (square plots named "this work") as compared to state-of-the-art capacitive electrodes (Fig. E: areal capacitance, Fig. F: volumetric capacitance). 
A
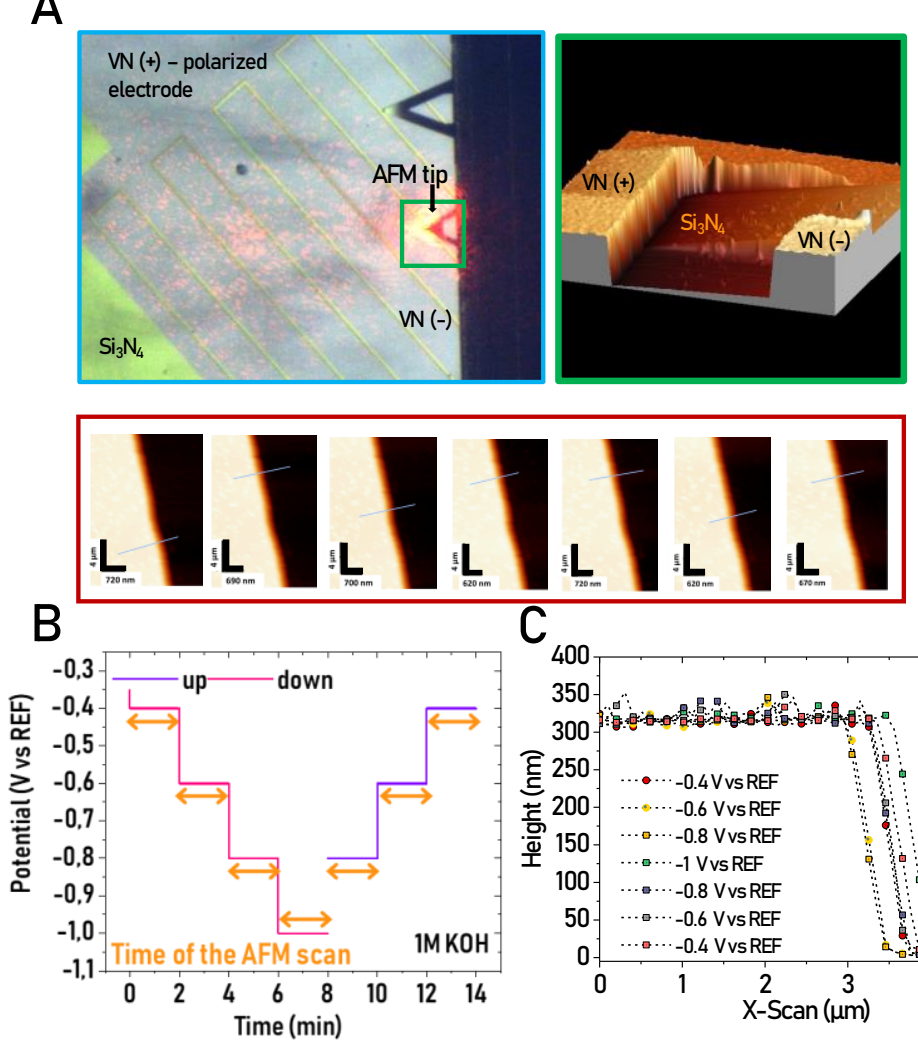

$E$

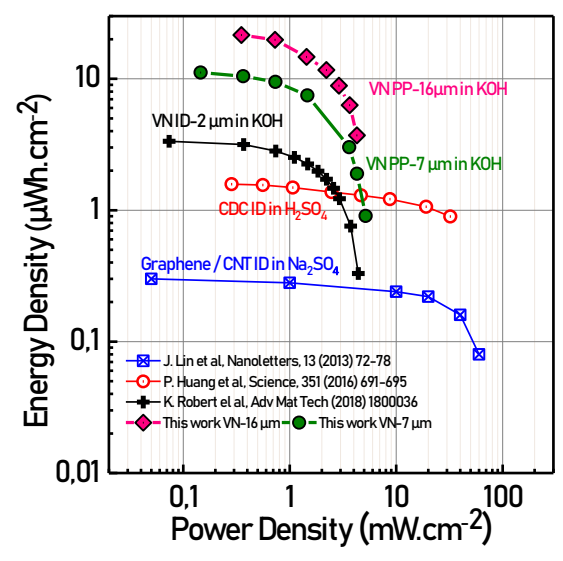

C
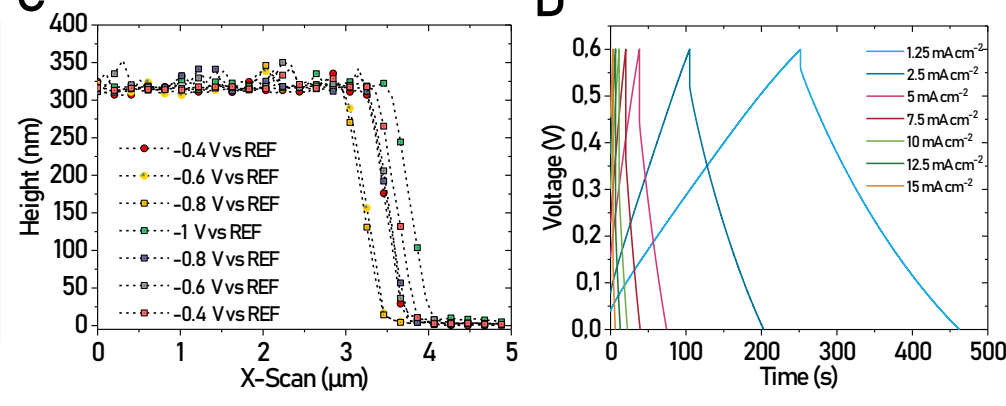

Figure 5 - A. In situ AFM analysis of a MSC in $1 \mathrm{M} \mathrm{KOH}$ electrolyte. B. Plots of the potential vs time between -0.4 and $-1 \mathrm{~V}$ vs $\mathrm{Hg} / \mathrm{HgO}$. C. Evolution of the $\mathrm{VN}$ height at different potentials. D. Charge / discharge profiles of a $16 \mu \mathrm{m}$-thick VN MSC at various current densities. E. Ragone plot of the MSCs in comparison to cutting-edge micro-devices operating in aqueous electrolyte. 


\section{References and notes}

1 J.-M. Tarascon and M. Armand, Nature, 2001, 414, 359-367.

2 A. Raj and D. Steingart, J. Electrochem. Soc., 2018, 165, B3130-B3136.

3 C. Lethien, J. Le Bideau and T. Brousse, Energy Environ. Sci., 2019, 12, 96-115.

4 C. Lethien, D. Troadec, P. Roussel, A. Demortière, E. Eustache, V. De Andrade, F.

Vaurette, J. Freixas, T. Brousse, P. Tilmant, L. Morgenroth and M. Létiche, Adv. Energy Mater., 2016, 7, 1601402.

5 J. I. Hur, L. C. Smith and B. Dunn, Joule, 2018, 2, 1187-1201.

6 P. Huang, P. L. Taberna, P. Simon, V. Turq, M. Respaud, C. Lethien, B. Chaudret, S.

Pinaud, B. Daffos, R. Laloo, K. Brousse, A. Demortiere and Y. Gogotsi, Science (80-. )., 2016, 351, 691-695.

7 M. F. El-Kady, V. Strong, S. Dubin and R. B. Kaner, Science (80-. )., 2012, 335, 13261330.

8 D. Pech, M. Brunet, H. Durou, P. Huang, V. Mochalin, Y. Gogotsi, P.-L. Taberna and P. Simon, Nat. Nanotechnol., 2010, 5, 651-654.

9 J. Y. Hwang, M. F. El-Kady, Y. Wang, L. Wang, Y. Shao, K. Marsh, J. M. Ko and R. B. Kaner, Nano Energy, 2015, 18, 57-70.

10 M. F. El-Kady, M. Ihns, M. Li, J. Y. Hwang, M. F. Mousavi, L. Chaney, A. T. Lech and R. B. Kaner, Proc. Natl. Acad. Sci., 2015, 112, 4233-4238.

11 E. Eustache, C. Douard, A. Demortière, V. De Andrade, M. Brachet, J. Le Bideau, T. Brousse and C. Lethien, Adv. Mater. Technol., 2017, 2, 1700126.

12 K. Robert, C. Douard, A. Demortière, F. Blanchard, P. Roussel, T. Brousse and C. Lethien, Adv. Mater. Technol., 2018, 3, 1800036. 
13 B. E. Conway, in Electrochemical Supercapacitors, 1999, pp. 259-297.

14 M. Toupin, T. Brousse and D. Bélanger, Chem. Mater., 2002, 14, 3946-3952.

15 M. Toupin, T. Brousse and D. Bélanger, Chem. Mater., 2004, 16, 3184-3190.

16 H. D. Abruña, M. A. Lowe, P.-L. Taberna, B. Dunn, V. Augustyn, S. H. Tolbert, J. W. Kim, J. Come and P. Simon, Nat. Mater., 2013, 12, 518-522.

17 H. S. Kim, J. B. Cook, H. Lin, J. S. Ko, S. H. Tolbert, V. Ozolins and B. Dunn, Nat. Mater., 2017, 16, 454-462.

18 C.-H. Lai, D. Ashby, M. Moz, Y. Gogotsi, L. Pilon and B. Dunn, Langmuir, 2017, 33, 9407-9415.

H. Sun, L. Mei, J. Liang, Z. Zhao, C. Lee, H. Fei, M. Ding, J. Lau, M. Li, C. Wang, X. Xu, G. Hao, B. Papandrea, I. Shakir, B. Dunn, Y. Huang and X. Duan, Science (80-. )., 2017, 356, 599-604.

20 M. R. Lukatskaya, O. Mashtalir, C. E. Ren, Y. Dall'Agnese, P. Rozier, P. L. Taberna, M. Naguib, P. Simon, M. W. Barsoum and Y. Gogotsi, Science (80-. )., 2013, 341, 15021505.

21 M. R. Lukatskaya, S. Kota, Z. Lin, M. Q. Zhao, N. Shpigel, M. D. Levi, J. Halim, P. L. Taberna, M. W. Barsoum, P. Simon and Y. Gogotsi, Nat. Energy, 2017, 6, 1-6.

22 B. Anasori, M. R. Lukatskaya and Y. Gogotsi, Nat. Rev. Mater., 2017, 2, 16098.

23 T.-C. Liu, W. G. Pell, S. L. Roberson and B. E. Conway, J. Electrochem. Soc., 1998, 145, 1882.

24 D. Choi, G. E. Blomgren and P. N. Kumta, Adv. Mater., 2006, 18, 1178-1182.

25 O. Bondarchuk, A. Morel, D. Bélanger, E. Goikolea, T. Brousse and R. Mysyk, J. Power Sources, 2016, 324, 439-446. 
26 P. Huang, M. Létiche, M. Respaud, B. Chaudret, A. Demortière, K. Brousse, S. Pinaud, L. Buchaillot, P. Simon, P. L. Taberna, B. Daffos, P. Roussel and C. Lethien, Adv. Funct. Mater., 2017, 27, 1606813.

27 S. Ouendi, K. Robert, D. Stievenard, T. Brousse, P. Roussel and C. Lethien, Energy Storage Mater., , DOI:10.1016/j.ensm.2019.04.006.

28 L. W. M. Lau, A. R. Gerson, B. P. Payne, R. S. C. Smart, M. C. Biesinger and A. P. Grosvenor, Appl. Surf. Sci., 2010, 257, 2717-2730.

29 T. Brousse, D. Bélanger and J. W. Long, J. Electrochem. Soc., 2015, 162, A5185-A5189.

30 P. Simon, Y. Gogotsi and B. Dunn, Science (80-. )., 2014, 343, 1210-1211.

31 J. Chmiola, G. Yushin, Y. Gogotsi, C. Portet, P. Simon and P. L. Taberna, Science (80-. )., 2006, 313, 1760-1763.

32 J. Chmiola, C. Largeot, P. L. Taberna, P. Simon and Y. Gogotsi, Science (80-. )., 2010, 328, 480-483.

33 P. Simon, B. Daffos, C. Lethien, K. Brousse, S. Pinaud, P. Huang, M. Respaud, B. Chaudret and P. L. Taberna, J. Power Sources, 2016, 328, 520-526.

34 M. Ghidiu, M. R. Lukatskaya, M.-Q. Zhao, Y. Gogotsi and M. W. Barsoum, Nature, 2014, 516, 78-81.

35 T. M. Arruda, M. Heon, V. Presser, P. C. Hillesheim, S. Dai, Y. Gogotsi, S. V. Kalinin and N. Balke, Energy Environ. Sci., 2013, 6, 225-231.

Acknowledgments: This research benefitted from the financial support of the ANR within the DENSSCAPIO project (ANR-17-CE05-0015-02). The authors would also like to thank the ANR STORE-EX and the RS2E for their financial support. The RENATECH network receives our 
utmost gratitude. XAS experiment was performed on the ROCK beamline at SOLEIL synchrotron, which is benefiting from a public grant overseen by the French National Research Agency as part of the "Investissements d'Avenir" program (Reference: ANR-10-EQPX-45). The authors declare no conflict of interest. All the authors wish to thank Anne Duchene for the sketch-up. KR achieved the deposition of VN films and the fabrication of on-chip MSCs. DS, DD and CL were involved in the in situ AFM analysis. KR, CD, AI, TB and CL were involved in the operando XAS. DT, MM, MH, PR and CL were involved in the TEM / EELS analysis of the VN films. KR, PS, NN and CL carried out the ToF SIMS / XPS analyses. 